\title{
Trickster carbon: stories, science, and postcolonial interventions for climate justice
}

\author{
Anita Girvan ${ }^{1}$ \\ University of Victoria, Canada
}

\begin{abstract}
This article proposes the idea of the trickster figure as a way to account for the shifting material, and cultural properties of carbon in the cultural politics of climate change. Combining scientific understandings of allotropy in chemistry - describing the property of certain elements to manifest in various highly diverse forms - and the insights of Caribbean trickster stories, trickster carbon enables novel understandings of the multiple workings and effects of carbon as a material and cultural element. Rather than granting 'carbon' a singular seemingly-scientific meaning or reducing carbon to a singular problem that master human agents can ever definitively trap or sequester, this notion allows us to view carbon's unique ability to shape-shift in a variety of contexts and for myriad agendas. Understanding carbon in this way provides more than simply a theoretical or imaginative 'romp'; rather, this lens enables both a critique of the ways in which carbon is mobilized in practice as a profit-generating tool of colonial capture and also a generative opening for understanding carbon's potential as a connector to more transformative associations and postcolonial politics. As an ambivalent and paradoxical figure, trickster carbon offers a powerful method of cultural way-finding through the urgent concern of climate change.
\end{abstract}

Key words: Trickster; postcolonial; decolonial; STS; stories; cultural politics of climate change; carbon

\section{Résumé}

Cet article propose l'idée du personnage du trickster comme un moyen de rendre compte du changement matériel et de propriétés culturelles du carbone, dans la politique culturelle du changement climatique. Combinant la compréhension scientifique de l'allotropie dans la chimie - décrivant la propriété de certains éléments de se manifester sous diverses formes - et la contribution des histoires de trickster caribéennes, le «carbone trickster» permet de nouvelles compréhensions des multiples travaux et effets du carbone en tant qu'élément matériel et culturel. Plutôt que d'accorder au «carbone» un sens singulier semblable à la science ou de réduire le carbone à un problème singulier que les humains peuvent définitivement piéger ou séquestrer, cette notion nous permet de voir la capacité unique du carbone à changer de forme dans divers contextes et pour une myriade d'agendas. Appréhender le carbone de cette manière fournit plus qu'une simple «farce» théorique ou imaginative. Au contraire, cet angle d'approche permet de critiquer la façon dont le carbone est mobilisé en pratique en tant qu'outil générateur de la capture coloniale, et de s'ouvrir à la compréhension de son potentiel en tant que connecteur aux associations transformatrices et à la politique postcoloniale. En tant que figure ambivalente et paradoxale, le «carbone trickster» offre une méthode solide pour lutter contre le changement climatique.

Mots clés: Trickster; post-colonial; décolonial; Etudes Scientifiques et Techniques; histoires; politique culturelle du changement climatique; carbone

\section{Resumen}

Este artículo propone la idea de la figura del trickster como una forma de representación de las cambiantes propiedades materiales y culturales del carbón en las políticas culturales del cambio climático. Combinando visiones científicas de alotropía en química - describiendo las propiedad de ciertos elementos para manifestarse en diversas formas - y las nociones de historias caribeñas de tricksters, el carbón trickster

\footnotetext{
${ }^{1}$ Dr. Anita Girvan, Faculty of Environmental Studies, University of Victoria, British Columbia, Canada. Email agirvan "at" uvic.ca. Many thanks to my family - especially June Girvan and Garry Girvan - who have shared trickster stories with me. Gratitude also to the Centre for Global Studies and the Indigenous Research Workshop group at the University of Victoria. A reviewer, through their familiarity with Caribbean trickster stories, generously helped inform my revisions. Abstracts were kindly translated by Celine Germond-Duret and Pablo Sepulveda.
} 
permite una novedosa manera de entender los múltiples mecanismos y efectos del carbón como material y como elemento cultural. Más que conceder al "carbón" un significado singular aparentemente científico, o reducirlo a un problema único que puede ser atrapado o dominado por los agentes humanos con autoridad, esta noción nos permite ver la habilidad única del carbón para cambiar de forma en una variedad de contextos para innumerables agendas. Entender el carbón de esta manera provee más que una "comedia" imaginativa y teórica; más allá, con este lente se permiten ambos, una crítica a las formas en que el carbón es movilizado en la práctica como una herramienta generadora de utilidades de una captura colonial, pero también un prolífico principio para entender el potencial del carbón como un enlace para asociaciones más transformativas y políticas poscoloniales. Como una figura ambivalente y paradójica, el carbón trickster ofrece un poderoso método de búsqueda cultural a través de la urgente preocupación del cambio climático.

Palabras clave: Trickster, postcolonial, decolonial, STS, historias, políticas culturales del cambio climático, carbón

\section{Engaging the paradoxes of carbon}

Carbon represents the best and worst of life. (Miodownik 2006: 6)

How can the paradoxes of carbon - as both foundational-to-life and disruptive-to-life - be held together in a way that allows for transformational possibility, at a time when such transformations are urgently needed? How can solutions/responses to climate change avoid the Promethean plunders and colonial inequities that are foundational to the problem of climate change itself? Building on insights from Caribbean trickster narratives and scientific narratives of carbon, I offer the creative mash-up of "Trickster Carbon" as a means of accounting for, and moving through the paradoxes of carbon at the turn of the millennia. In blending these two seemingly different ways of knowing about the world, I aim not for a tidy reconciliation between science as fact and stories as values, but for a way of recovering a certain generative indeterminacy in each account, where fact and values intermingle. There is no way to rid science of its cultural bearings, nor is there a way of decoupling stories from the material worlds they create. Further, as both a biophysical and a cultural phenomenon, climate change demands engagements that acknowledge this entanglement and that work with cultural and physical elements, rather than seeking to hold these apart. This is necessarily messy work that transgresses structured knowledge, defers expertise, and promises no easy solutions to climate change and other pressing ecological issues. The wager is, however, that such transgressive work is necessary in a world that is attempting to manage a transgressive carbon that will no longer do (never did) 'our' ${ }^{2}$ bidding, despite attempts to tame it in our service and lock it away when it is unruly.

As cultural stories that feature paradoxical protagonists - like Anansi the Spider and Brer Rabbit - who shift in form and habit over iterative accounts, trickster stories hold particular promise as intermediaries between that which is thought to be tangible, structured and certain and that which is revealed to be intangible, shifting and uncertain. At a time of profound shifts and potentially abrupt political and ecological change, trickster figures offer crucial understandings of such dynamism at work. With their reach into the past of cultural history, trickster stories themselves are not new, especially for certain communities and cultures that have sought to understand the world as a place of dynamic forces and energies that include larger-thanhuman and spiritual connections. They often feature anthropomorphized creatures that take various forms animal, human, fool, god/creator. Further, for cultures that have undergone the violent upheavals of colonialism or slavery, these tales have also been prescient as a means of way-finding through shifting and difficult power struggles and the legacies that ensue. In these cases, trickster figures often appear in stories to have been duped into a submissive or subservient role, only to reappear as the narrative unfolds as a force to

\footnotetext{
${ }^{2}$ I use 'our' and 'we' provisionally in the article to refer to a global collective (internally differentiated) that is affecting and affected by climate change, even as I unpack the hidden asymmetries buried within this term in the latter half of the article. As Cary Wolfe enigmatically suggests with regard to climate change "there is no 'we', yet there is nothing but 'we'" (Wolfe 2011, personal communication). Such a statement reveals a certain need to keep the universal/global and the particular/local in play, as mutually-troubling categories.
} 
be reckoned with (though ambiguously so). Constantly with us through human histories, even as they shift in form and meaning, tricksters offer continuity with certain prescient stories of the larger-than human condition.

Although "Trickster Carbon" picks up on important elements of Anansi and Brer Rabbit trickster stories from my Jamaican family history (described further in the latter half of the article), the novelty of this story at a time of climate change is the addition of a seemingly scientific word - carbon - into a cultural matrix. Like diverse trickster stories, carbon has been with us throughout human history, shifting in form and meaning in ambiguous ways. As Timothy Mitchell reminds, there is no way of telling the story of human history, geo-politics and the creation of modern institutions like democracy, without recognizing the fundamental and ambivalent role of carbon (2011). This mash-up of Trickster Carbon offers a particularly timely narrative where modern enlightenment stories of human mastery appear particularly susceptible to their shifting cultural and material bearings at the turn of the millennia. Like others of its kind, this trickster story offers no definitive heroic escape of human master agents from their Earthly tethering; rather, the narrative features a complex struggle within and amongst larger-than-human carbon relations where the story is still unfolding in ways that remain unpredictable. To find bearings in such a terrain means shifting from dominant delusions of mastery, to perceiving through humility. It is in this shift from control and domination to contingency and shared vulnerability that we may find our most hopeful footing on shifting ground.

\section{Promises and risks of modern science}

I begin below with insights from modern scientific understandings of carbon as an element. To be clear, I am not a physical scientist, but one who engages with science as one way of knowing in the alwayspolitical realm of climate change. My scholarly learning has come largely from the social sciences and the humanities, with an emphasis on the creative world-making power of words and tropes in questions of political ecology. Nonetheless, I have always had an appreciation for what I think is the best attribute of the sciences: the quest for partial understandings amid an infinite field of uncertainty and unknowability (Haraway 1988). When I evoke scientific narratives, therefore, I do so from the perspective of one who is interested in what the language and epistemologies of science offer in terms of expressions of shifting, contingent power-laden knowledge in a changing larger-than-human world.

As a scholar of cultural politics of climate change, however, I am also critical of the ways in which climate science can be dominantly mobilized to the exclusion of other ways of knowing, with damaging political and ecological effects. ${ }^{3}$ Under the banner of the 'urgency' of climate change, it is possible to use scientific knowledge to impose a range of (neo)colonial mitigation strategies, such as the Reducing Emissions from Deforestation in Developing Countries (REDD), which perpetuate inequities (Batnagar and Goldtooth 2015; Chomba et al. 2016). McGinty and Bang identify the problem whereby the very Euro-Western nationstates who have created the largest impacts upon climates also are the singular generators of the scientific knowledge deemed "necessary" for understanding climate change problems and solutions (2016). Further, only too often, this lens perpetuates colonial asymmetries where local Indigenous societies are the first to be harmed by shifting climates (Kunuk and Mauro 2010), and they and their lands are also subject to increased control under the managerial logics of carbon sequestration (as I discuss further below).

To begin here with science then, is not to reify a certain scientific understanding of carbon as an element to be managed, but rather to expose the cultural and shifting meanings of carbon even within modern scientific accounts, which are built upon the turning of carbon as an allotrope.

\section{Allotropic carbon}

A cursory glimpse at carbon's etymological and elemental-chemical origins reveals an entanglement of "nature" and "culture" at its roots. While what is now called carbon has always been a foundational element of planetary life, it was not scientifically identified as such until the late $18^{\text {th }}$ Century when chemists began to isolate the various 'elements' of which matter is made. The word, carbon, derives from the Latin for charcoal

\footnotetext{
3 It also bears mentioning that climate and ecological science itself can be subjugated to other political interests, as the US
} is experiencing with the gutting of environmental protection under the Trump administration. 
or "burning coal" (carbo), but different words were used to describe other elemental forms of carbon like graphite and diamonds, that were not associated with the fuels that people used in antiquity. Carbon is therefore 'modern' as a scientific-discursive element, although ancient in its various manifestations in human history, and prehistoric in its material conditioning of planetary life. Because of these varying manifestations, scientific understandings of carbon are still evolving, even as carbon itself is always on the move and shifting with the rhythms of planetary life.

As a chemical element, carbon exhibits the property of allotropy: "the existence of a chemical element in two or more forms, which may differ in the arrangement of atoms in crystalline solids or in the occurrence of molecules that contain different numbers of atoms" (Encyclopedia Britannica). ${ }^{4}$ Allotrope combines the Greek origins of allo meaning "other" and trope meaning "turning toward", or "affinity to." Thus, the epistemological contributions of chemistry foreground the tendency of elemental carbon to turn toward other or multiple forms, even in its elemental manifestations as: diamond, graphite and more recently, fullerenes and fullerene-related nanotubes (Hirsch 2010). In other words, the embodied forms of carbon as an element are highly diverse because of the relational encounters and processes in which it is involved.

What is remarkable is that carbon as an element can take on such widely divergent structural forms depending on the arrangement of atoms; each of these forms not only looks different to the naked human eye, but generates different socio-ecological and political relations and effects. The politics and affects associated with diamonds as symbols of wealth, devotion and fraught geo-political relations, are markedly different from those generated by the allotrope of graphite, as an early material used by humans to record information. Arguably much of the 'success' of the human species has been achieved through using the elemental form of carbon, anthracite (coal) which was burned by early humans, used by Romans and more notably (and ambivalently) fueled the Industrial Revolution. Even as humanity is currently recognizing this human history with coal and carbon-based fossil fuels as a highly fraught one, we are turning to still other forms of elemental carbon to help power human societies. Recently, the carbon allotrope of graphite has been gathering value as a key component in a growing market for fuel cells and nuclear reactors (Lifton 2012). Meanwhile, the newest discovery of carbon nanotubes apparently holds the promise of "solving humanity's most pressing problems", including ecological issues related to climate change, according to the Smalley Institute Grand Challenges research group at Rice University. ${ }^{5}$ Of particular note is the proposed promise of carbon nanotubes in the increasingly necessary technologies of water desalination (Das et al. 2014). Paradoxically, then, a certain elemental carbon (though strictly in its compounded bonding through combustion with oxygen as $\mathrm{CO}_{2}$ ) takes on the burden of being the material index of the problem of climate change, even as certain other carbon allotropes, such as carbon nanotubes, promise to fix problems associated with food, water and other environmental issues that are brought about or exacerbated through climate change.

\section{Discursive carbon}

Notably, carbon as a discursive or cultural element displays a similar polyvalence, taking on different forms and arrangements according to myriad relations and processes. In other words, carbon as a trope - a turn of phrase or figure of speech - is similarly susceptible to allotropic attachments that manifest in different cultural and material forms (eg. carbon as commodity, carbon as index of greenhouse gases, carbon as life). There is a certain dissonance that is posed by carbon as a stand-in for the evils of climate change; the actual concern indexed by this trope features a set of carbon compounds - not carbon in general (or in isolation) - as well as other greenhouse gases. The term carbon dioxide equivalents $-\mathrm{CO}_{2 \mathrm{e}}$ - has become the scientificallyinformed policy-oriented term that is most commonly used to calculate a conglomerate of greenhouse gases in key reports such as the Intergovernmental Panel on Climate Change (IPCC) Assessment Reports. In many

\footnotetext{
${ }^{4}$ Encyclopcedia Britannica Online, s. v. "allotropy", accessed May 09, 2017. http://www.britannica.com/EBchecked/topic/16560/allotropy.

"Smalley Institute grand challenges: nanoscale science and technology" (2008) Rice University http://cnst.rice.edu/content.aspx?id=246
} 
public accounts, however, the term is usually reduced to simply 'carbon. ${ }^{6}$ Greenhouse gases are notoriously invisible and complex in their atmospheric interactions, suggesting that one function of carbon in such public discourses is to reduce the complexity and make visible and tangible something that cannot be seen. Carbon as a lay-scientific term, therefore, has entered public discourse recently as a kind of vague signifier that connects to coal and other fossil fuels that are burned and produce unpleasant, even harmful effects; thus, it may be that carbon easily stands in as a measure of negative atmospheric effects. But carbon is also implicated in all kinds of other cycles (materially and metaphorically) that come to influence its role in everyday life as well as in historical patterns. Understanding this allotropic property of carbon as a chemical and discursive element suggests that relations, processes and bonding capacities matter profoundly in its manifestations, its movements, its promises and risks. This is not to say these discursive forms are "natural" or elemental; rather they are political, contested, and consequential. My purpose for explicitly considering carbon's discursive allotropic character is twofold. First, understanding carbon's non-essentialist allotropic qualities functions to unsettle the ways in which carbon as a trope is used to grant authority to questionable practices by virtue of its assumed empirical-quantitative status (my forthcoming book on carbon footprint metaphors details the ways in which this metaphor can, at times legitimize a profit-oriented carbon offset economy, Girvan 2017). Second, explicitly recognizing the semiotic and material turning of this element situates carbon foundationally as a kind of trickster figure - both material and metaphorical itself - whose shiftiness is all-too-well becoming clear at a time of changing climates.

Carbon has been an indispensably constant figure (even in its shiftiness) that has shaped planetary life and enabled human progress, though unevenly so. Carbon has enabled fire technologies, internal combustion engines and even aeronautical engineering technologies that paradoxically promise to reduce greenhouse gas emissions from air travel through reductions of airframe weight brought about through the use of lightweight carbon fibre (Edwards 2008). However, carbon is also now turning on humans - or perhaps more accurately, dominant human societies are overturning (hydro)carbons - such that carbon seems at times, a duplicitous associate. 'Our' fraught history with this element suggests that, from an anthropocentric perspective, "carbon represents the best and worst of life" (Miodownik 2006: 6). Of course, paradoxically, the contested metaphor, Anthropocene, also gestures at 'humanity' as a duplicitous associate - both in terms of certain dominant societies of humans and their disproportionate impact on other humans, and in terms of the human species' generalized effects on our fellow species. But rather than reading carbon (or ourselves) as duplicitous, the more pressing task is to trace the ambivalent possibilities of certain associations and processes in which societies and carbon are entangled. To nuance Mark Miodownik's statement above: carbon's allotropic associations and processes present both promises and risks. Carbon is enigmatically present in culturalmaterial entanglements as both an enabler and an impediment, both a problem and a solution.

\section{Carbon compounds}

Upon the allotropic formation of carbon as an element, another layer of shiftiness occurs in its compounded forms. Carbon as material actor has a unique ability to "bind to itself and to nearly all elements in almost limitless variety" (Hirsch 2010: 868). Even as humanity seems to be attempting in earnest to phase out the extraction and combustion of elemental coal/anthracite ${ }^{7}$, other compounded forms of carbons are being pitched as "bridge" fuels in a transition from conventional fossil fuel to renewables. For instance, carbon compounded with hydrogen as $\mathrm{CH}_{4}$, methane, is the main component of natural gas that is found underground and under the sea. The controversial hydraulic fracturing or "fracking" method of extracting this

\footnotetext{
${ }^{6}$ For example, the city of Victoria in Canada launched a new "cut the carbon" campaign with the roll-out of new trash bins. Inscribed upon these bins was the motto "cut the carbon" accompanied by the image of some bubble-like circles (presumably a representation of carbon?) In the documents linked below the bubbles are filled in with images representing buildings, transportation, etc, but the original bins allocated to each home simply contained the bubble circles. http://www.victoria.ca/assets/Departments/Sustainability/Documents/Cut\%20the\%20Carbon\%20Gallery\%20Display\%20 Boards.pdf.

${ }^{7}$ The years 2015-2016 marked a crucial period for legislating the phase-out of coal in the US with the Clean Power Plan (2015); China made a similar commitment in 2015, as did certain provinces in Canada (Ontario) and the US (Oregon). In 2016, Vietnam's Prime Minister also announced the phasing out of coal.
} 
bridge fuel is attributed gains in energy self-sufficiency and economic growth in the US and elsewhere, where conventional oil reserves are either waning or becoming more difficult to access. Liquefied Natural Gas (LNG) has also been represented as a "bridge" fuel between conventional oil and renewable energy in its potential capacity to lower greenhouse emissions. However, many are currently questioning the calculus of net decreases in greenhouse gas emissions through this bridge fuel, as recent leaks of methane - a greenhouse gas with a warming effect 25 or more times greater than carbon dioxide - have produced disastrous warming effects (not to mention the issue of air and water contamination and health impacts for publics on the frontlines of these operations). ${ }^{8}$

As this massive experiment in up-ending carbon continues, other forms of compounded carbon are emerging as destructive for much of planetary life as it is presently configured. While atmospheric impacts of hydrocarbon extraction and combustion receive the most attention under the banner of climate change, marine impacts attest to how carbon dioxide absorbed by the oceans is rapidly changing the ocean's chemistry. $\mathrm{CO}_{2}$ combined with water $\left(\mathrm{H}_{2} \mathrm{O}\right)$ and carbonate ion $\left(\mathrm{CO}_{3}{ }^{-2}\right)$ produces $\mathrm{H}_{2} \mathrm{CO}_{3}$, carbonic acid. ${ }^{9}$ According to the National Oceanic and Atmospheric Administration (NOAA), this chemical reaction has increased the acidity of the ocean by thirty percent since the beginning of the Industrial Revolution. While calcium in its partnership with carbonate has enabled the foundational building blocks for shells in sea life and all other life that follows, the rapid up-take of anthropogenic $\mathrm{CO}_{2}$ by the oceans has severely and negatively affected this relationship. Once thought of as a promising 'solution' to excessive atmospheric $\mathrm{CO}_{2}$, the ocean's absorption of carbon dioxide and the resulting acidification is now understood as profoundly problematic for marine ecosystems that affect all manner of Earthly life. Seemingly, just as we ${ }^{10}$ think we have a handle on carbon's movements and how we might manage them, carbon relations shift, revealing another attachment or process that hasn't yet been recognized.

\section{Discursive carbon compounds}

As Nelya Koteyko's investigations of lexical "carbon compounds" reveal, linguistic or discursive carbon is equally promiscuous in its compounding attachments. Koteyko and Brigitte Nerlich use the tools of "corpora linguistics" or "corpus linguistics" - a computer-assisted method of collecting and tracking instances of words in texts to derive abstract rules by which language functions - to track carbon compounds, conceived linguistically rather than chemically (Koteyko 2010; 2012; Nerlich 2012). Their studies offer an explicit engagement with the public spaces in which these novel carbon compounds occur as profoundly important political sites:

Carbon compounds in this lexical sense, seem to have overtaken 'eco-compounds' in popularity, that is words which use eco- as a prefix to signal various environmental concerns and issues. A whole new language is evolving using carbon as a hub, which needs to be monitored and investigated in order to discover how climate change and climate change mitigation are framed... (Nerlich 2012: 32)

The forceful emergence of proliferating carbon compounds constitutes a whole new language (and consciousness), but as these scholars point out, these terms have been adopted without extended critical reflection on how political representations are "achieved with the help of which lexical means" (Koteyko 2012: 25). Although Nerlich's suggestion above of 'monitoring' lexical carbon compounds offers a potentially

\footnotetext{
${ }^{8}$ Conley et al. (2016) suggests that the Aliso Canyon, California methane leak in 2015-2016 has contributed enormous radiative forcing effects equivalent to the annual effects of half a million passenger cars. This leak has produced the largest climate impacts of all such leaks in US history, and will put California far behind its emissions targets for this year. The 97,100 metric tons of methane leaked from this one single source is equivalent to the annual emissions produced from the $\mathrm{CH}_{4}$ sector in a medium-sized European country.

${ }^{9}$ http://www.pmel.noaa.gov/co2/story/What+is+Ocean+Acidification\%3F

${ }^{10}$ Again, the 'we' here is a troubled we, not a universal one since not all humans share this Enlightenment myth of managing carbon for once and for all.
} 
important scientific-managerial approach for critically accounting for these compounds, I offer trickster stories as a supplement to suggest that we can never completely master the monitoring of carbon compounds, nor can we lock them in as simply static framing devices. Nonetheless, this work on lexical carbon has traced important patterns and connections that are shaping dominant approaches to climate change, and therefore reveal some of the shifting shapes that trickster carbon can inhabit.

The political risks attaching to carbon compounds' tropological movements feature carbon as an object to be managed and mastered by intentional human agents in human-centric systems, dominated by the Global North. Crucially, many of the carbon compounds that have most productively taken hold as part of climate change solutions are those that bolster what Steven Bernstein calls "the compromise of liberal environmentalism" which promotes "liberalization in trade and finance as consistent with (even necessary for) global environmental protection" (2000: 474). Carbon compounds become entangled with this cultural history. As Koteyko suggests:

[t]he first carbon compounds to emerge in the English speaking news, such as carbon trading and carbon credits were part of this shift to market-led climate change mitigation. Corporate support for climate measures became evident in the wave of activities and initiatives to manage emissions through product and process improvements, and the exploration of new market opportunities offered by carbon trading as well as by voluntary offsetting schemes. (Koteyko 2012: 26)

Gavin Bridge argues that carbon storage and trading logic promotes the "enclosures and transformations necessary to produce sequestration landscapes as objects of speculation and instruments of profit" (2011: 824). While it is important to recognize the importance of trees and soil and their relations with carbon in efforts to avoid deforestation, the (partial) recovery of forests as 'carbon sinks' may initiate new forms of colonial dispossession. Building on David Harvey's critique of capital "accumulation by dispossession", Bumpus and Liverman call this process "accumulation by decarbonisation" (2008: 142). This process involves the creation of:

...rights to emit carbon (pollution permits) ... that become commodified and privatized, traded with transaction fees, and allocated and regulated by international and state institutions under conditions of unequal exchange between developed and developing countries, northern companies and southern communities. (Bumpus and Liverman 2008: 142)

The Indigenous Environmental Network (IEN) is shedding new light on the ways in which the United Nations Reducing Emissions from Deforestation and Degradation (REDD) program for climate change mitigation is dispossessing peoples of their traditional land. By asserting control over trees, which under the lens of "ecosystem services" provide carbon sequestration, the UN is initiating what the IEN calls "a carbon market mechanism, land-grabbing false solution to climate change that could potentially cause genocide." (Bhatnagar and Goldtooth 2015). The IEN calls these "false solutions" because instead of insisting on binding emissions targets in developed countries, REDD proposes "the Global South as sponges for industrialized countries' pollution" (ibid). In so doing, groups like the Sengwer People in the Embobut Forest of Kenya are being violently evicted and facing extinction (World Rainforest Movement 2014). Understanding the ambivalence of allotropic carbon in these stories reveals the duplicitous ways in which carbon can be evoked.

Given that carbon in its material or cultural forms does not bond "naturally" with a specific form or political agenda, carbon compounds must be read as profoundly ambivalent characters in the cultural politics of climate change. Their ambivalence does not, however, negate their important role; on the contrary, their very shiftiness offers generative insights for moving through the multiple-storied carbon relations that require multiple accounts (beyond simply carbon accounting as a quantitative pursuit).

What is at stake here is the creation of an opening to other ways of knowing about carbon and climate change, its complex problems and complex solutions. I am not arguing for abandoning scientific attempts to 
grapple with $\mathrm{CO}_{2}$; indeed, without these scientific understandings, we would not understand planetary climate change to the extent that we do. I am advocating, however that science-based managerial accounting of carbon and proposed solutions be infused with accounts that centre the material and cultural shiftiness of carbon in its interactions with human and non-human elements. I propose that the political and ecological promise of carbon as a trickster (allo)trope lies in its capacity as a connector that brings into visibility global societal relations as well as what Jane Bennett calls a "vibrant materiality that runs alongside and inside humans", but is also avowedly larger-than-human (Bennett 2010: viii). Recognizing the vibrant materiality of carbon affords a lively force to entities normatively constructed as "passive matter" (Bennett 2010: vii). Here science's own generative principal of allotropism combines with a necessary postcolonial/decolonial cultural lens offered by trickster stories.

\section{Diasporic Trickster bearings}

If the promising notion of allotropy from science becomes attached to Euro-Centric colonial impulses that seem to further exacerbate climate change as a political and ecological issue, then one important intervention occurs in the decolonization of knowledge about carbon and wider socio-ecological relations. Trickster stories brought into this current moment offer a generative corrective to the notion that "ideas, information, expertise and knowledge travel only from the Global North to the Global South" (Anatol 2017: 151).

In order to contextualize the story at stake here, I briefly situate the circumstances that led me to entertain carbon as a trickster - a particularly loaded and important figure for many societies, especially those grappling with colonial legacies. As a multi-racial ${ }^{11}$ settler who doesn't 'pass' as Canadian in the ways that Canadian is normatively constructed, it is my particular privilege/challenge to find narratives that resonate with life-worlds lived in complexity in what is often perceived as a transgressive body/skin/hair. ${ }^{12}$ This position does not grant me what Eve Tuck and K. Wayne Yang critically call the "move to innocence of settler nativism." (2012: 12). As a product of settler-colonial education, and more importantly land-based structures of colonized "property" - first on Lheidli T'enneh territory and now on Lekwungen and WSÁNEĆ territory - I learned far too belatedly how my presence on Turtle Island/"Canada" is premised upon extractive violence that is far from innocent. In fact, I now realize, as Tuck and Yang point out, that a "logical end" to my childhood longing to be in an uncomplicated relationship with Canadian identity is "actually an investment in settler colonialism" (2012: 18). This understanding, along with an understanding of what Leanne Betasamosake Simpson (2013) highlights as the mindset of colonial "extractivism" at the heart of the problem of climate change, has led me to attempt to find other stories and possible ways of being in the world that get lost in erasures through colonial processes.

My quest to find other stories is not a quest to apprehend colonial processes everywhere as the same; these are everywhere different and need particular responses. Nor does this story constitute my fulfilling of settler responsibility to those whose land I am now inhabiting. This on-going process of accountability and responsibility requires on-going processes of un-learning, re-learning, and shifting land-based power relations on Lekwungen and WSÁNEĆ territory where I am currently situated, as well as more widely on Turtle Island and beyond. As the Standing Rock Dakota Sioux assert, these politics of extractive land relations are

\footnotetext{
${ }^{11}$ I do not wish to reify the category of 'race' here as a biological fact. Race is a social construct that I wish did not exist, but this construct does indeed produce effects on specific bodies and ecologies that cannot be ignored, despite claims that we are living in a 'post-racial' world.

${ }^{12}$ A common question asked of me upon being introduced to non-racialized 'Canadians' was: "Where are you from?" The answer, "Prince George, British Columbia, Canada" (a highly settler-infused answer, I now realize) prompted the question, "No, where are you really from?" Childhood nicknames 'given' to me by childhood classmates included "Bahama Mama" "Aunt Jemima" and "Blackie." While none of these experiences negates the many settler privileges I have had, these "microagressions", when taken together, marked my identity as somehow transgressive to Euro-Western settler norms. This has been an ambivalent process for me since it has marked my own (in)capacity to be 'simply Canadian', but in positive terms, this process has also permitted me: 1) to understand Canadian state-based identity as an inherently fraught identity in terms of long-standing relations with First Nations; and 2) to explore and re-connect with Jamaican legacies (including trickster stories) that might inform understandings of colonial relations built into climate change politics.
} 
intimately connected with hydrocarbon-based industries that further exacerbate socio-ecological harms well into the future (Archambault 2017). My own attempt here, is to begin to shift the stories that orient actions perpetuating such harms; the trickster stories I explore here from my family roots in Jamaica offer only one partial response to the need to dis-orient from colonial bearings in cultural politics of climate change. One of the insights of trickster stories in the plural emerges from their very plurality; that is, these stories convey the meanings of multiple worlds at play.

Like many Caribbean families, my Jamaican family is riddled with the tensions of the historical overlays of European settlers upon Taino/Arawak Indigenous peoples of the islands, and waves of people read as 'slaves' who were forcibly removed from the African continent. A Jamaican national consciousness is indeed built upon the foundations of these groups and more, as the Jamaican moniker "out of many, one people" attests (though in practice, this seeming unity is troubled, as it is in every nation). Because of these complex relations and processes, I grew up with a complex blend of stories that were read to me in various world Englishes by my multiple-storied and linguistically-gifted Jamaican-born father. My parents read us stories of Brer Rabbit, the trickster that figures prominently in stories of the plantations of Southern U.S. These stories were also an integral part of my father's up-bringing in Jamaica, despite the many differences in lived experiences between African-Americans and African-Caribbean peoples. My father's multiple accents in reading various stories seemed to signal the subtleties of words and figures that house multiple and paradoxical meanings in different contexts revealing messy worlds at play. These shifting meanings and paradoxes were particular poignant when he would read the trickster stories of Brer Rabbit.

\section{Brer Rabbit}

I linger for a moment on Brer Rabbit stories because I suspect that most readers of this article will be more familiar with this trickster ${ }^{13}$ than the Anansi trickster story that follows; however, I will return to Anansi the spider below since this trickster offers specific insights that I would like to tease out further. The stories of Brer Rabbit are themselves shifty in that their origins are diverse and in some cases, contested. Rabbits are known as tricksters in Indigenous stories from the Creek and Cherokee nations of the American southeast where rabbit is called Pasikola (Birchfield 1996) and in traditional tales of Leuk the hare from North Africa (Rutledge 2013). It would seem that contact between African slaves and Indigenous peoples in the American southwest has created what some scholars call an "African-Native American" body of literature that influenced the movement of these trickster rabbit stories (Brennan 2003; Gay 2003; Vest 2000). Further complicating this history is the fact that the first written collection of these Uncle Remus stories was produced by a white man, Joel Chandler Harris who recorded the stories told orally to him by African-Americans. To some, Harris' created narrator, Uncle Remus is a caricature of a "faithful darky" who pleasantly accepts the conditions of his servitude (Lester 1987, xiv). For Alice Walker, the Harris collection presents a violation of the richness of the oral stories and a form of cultural appropriation that was reproduced when Disney produced its 1946 animated version of these stories in the film Song of the South (Walker 2012). Nonetheless, stories rarely faithfully represent singular authorial intent and they have a life much greater than any one teller/writer. Even in her criticism of Harris, Walker reminds us that the richness of Brer Rabbit stories lives on in the bodies and traditions of the culture lived beyond the confines of a single-authored book/Disney movie. With all of these fraught histories in mind and with an attention to avoiding the de-politicizing move of evoking a flattened out, generic, transnational Indigenous trickster, I am here attempting to pull out generative themes that I received from my particular situated perspective of particular stories.

In the well-known story of Tar Baby, the trickster Brer Rabbit first gets caught by the fox in the sticky trap of the Tar Baby and then himself outsmarts the fox. In many tellings of the story, the initial plan to trap Brer Rabbit emerges as a result of his greedy appetite for the vegetable garden. In this particular story, Brer Fox first tricks Brer Rabbit into thinking that the Tar Baby he has made is a living thing that can talk. When Brer Rabbit talks to an unresponsive Tar Baby, the seemingly stupid rabbit winds up, punches and kicks the tar creature repeatedly out of frustration and finds himself stuck in a sticky mess. Upon realizing he has been

\footnotetext{
${ }^{13}$ Here, I wish to thank the Trinidadian reviewer of the article (Dr. Ainka Granderson - ed.), for pointing out that Brer Rabbit takes the form of Compère Lapin in the French patois-speaking Caribbean and in New Orleans.
} 
tricked, Brer Rabbit then, in turn, outsmarts Brer Fox by using words and reverse psychology to get himself in another more helpful material situation. He suggests that whatever Brer Fox does, he should not throw him into the briar patch. Of course, this request prompts a vindictive Brer Fox to toss him into the briar patch. Little does Fox know that the briar patch is a favoured environment for Brer Rabbit and one that is conducive to a rabbit ridding himself of sticky tar. At the end of this tale, a giggling Brer Rabbit emerges on the other side of the briar patch and gloats, "I was born and raised in the briar patch, Brer Fox" (Lester 1987). Importantly in this story, the trickiness shifts from the fox to the material stickiness of the tar (baby) who is part of the equation, then cycles to the rabbit who, in his/her/their relationship to the briar patch, eventually evades the trap. A number of other stories reveal Brer Rabbit to be both wise and foolish in his interactions with his fellows.

The collection of Brer Rabbit stories defies an easy take-away lesson; nonetheless, these stories offer a profound method of cultural way-finding through complexity. Brer Rabbit and other characters act in polymorphic ways as the trickster and the tricked. The characters exist in a world of distributed agency where unintended consequences are part of the dynamics of any action/event. As many have testified, these ambiguities of the stories are most certainly a reflection of the complexities of plantation life in which characters' transformative powers are masked so as not to appear transgressive of the order of the day (Harris 2000; Walker 2012). As Alice Walker contends, they also served as points of critical self-reflection for African-American folk culture, for despite the fact of their oppression and the removal of their humanity by oppressive cultural processes, people were still resilient and understood that there was complexity and some degree of choice in their own lives, actions and thoughts, even under highly constrained circumstances. From this perspective, trickster sensibilities suggest that resilience might arise from seeing beyond the reductive binaries of oppressor-oppressed and glimpsing a much more dynamic, if still troubled material and social world. Such paradoxes taken into the realm of carbon, enable a more dynamic lens to view shifting interactions, as I tease out below.

\section{Anansi the Spider}

My understanding of trickster ways of knowing further deepened through Anansi stories of the Caribbean. The stories of Anansi originate among the Asante/Ashanti people of West Africa (what is now known as Ghana) where Anansi means 'spider' in the Akan language of the region (Aardema 1997). The Anansi stories collectively convey the origins of the peoples in the region and their on-going trials and tribulations in their territory. Beginning in the 15th century, this region of West Africa, then known as the Gold Coast, became a major source of the 'free human resources' for colonial enterprise in the Americas through the slave trade. Much evidence suggests that as many as half of the people forcibly transported from this region went to the plantation slave culture on the island of Jamaica, thus accounting for the predominance of Anansi stories in Jamaica (Marshall 2012; Sherlock 1954). Jamaica remains a rich site of these oral stories which have been transcribed into numerous written collections.

Notably, key differences emerge in the movement of enslaved peoples and Anansi stories across the Atlantic and as they settled into their Caribbean contexts. In her extended treatment of Anansi's journey across the Atlantic, Emily Zobel Marshall makes the case that in Asante stories, Anansi's transgressive acts paradoxically served to reinforce community rules whereas in a Jamaican "plantation setting, Anansi could invert the social order without paradoxically upholding it...Anansi had the potential to function as a character who could destroy an enforced and abhorrent social system rather than just test the boundaries." (Marshall 2012: 48).

In the founding story of the original Asante tale, Anansi appeals to the Sky God/Nyame (rather than Tiger in the Jamaican version) that he should be the holder of the intergenerational tales on behalf of "our earth people" (Aardema 1997: 2). The sky God gives Anansi a series of seemingly impossible tasks to perform. Anansi completes the tasks, but crucially, he does so with the help of his partner, Aso and a host of other creatures. Sky-God/Nyame concedes the stories to Anansi, but Nyame's place in the cosmic order is not disrupted by this move; indeed, Anansi continues to serve Sky-God/Nyame who continues to hold the power (Marshall 2012: 54-55). 
In the beginning of the Jamaican version of the never-complete series, Anansi insists to the Tiger, king of the forest (rather than Sky God/Nyame) that the collection of stories be told with him as the central figure. While the suggestion prompts laughter among the animals in the forest who regard Anansi as the weakest, Tiger smugly offers that it might be possible if Anansi is able to fulfill a task through which he would earn the right to be the centre of each story. The task in this case involves the seemingly impossible trial of bringing Snake back to Tiger (this is one of the tasks in the original Asante story as well). After unsuccessfully attempting a number of physical traps for Snake, Anansi ends up using his wits to lure Snake by appealing to Snake's conceit that he is the longest animal. Suggesting that the only way to ascertain Snake's superlative length in the world was to bind him to a felled bamboo tree as a way of measuring him, Anansi dupes Snake into assuming a vulnerable position that leads to his entrapment and the completion of Anansi's impossible task. Tiger must accept the fulfillment of the task, the stories become Anansi Stories from that moment, and the animals in the forest no longer think of Anansi as the weakest among them (Sherlock 1954).

After hearing this first story, one is tempted to think of Anansi as a master agent that can outsmart God/Tiger. But one cannot rely on this stable identity of the hero in subsequent episodes. In one story, Anansi seems to be the hero, with an ability to dupe the reigning forces and shape an entire cosmology based on stories that centre on him. In another, Anansi's own laziness and greed lead to unintended consequences. Such ambiguities reflect the ways in which Jamaican Anansi stories were "mechanisms of survival and sources of wisdom or knowledge, which could, in certain contexts, translate into resources for resistance and play a part in fueling slave revolt" (Marshall 2012: 92). Marshall is careful in her analysis of Anansi stories to insist that not all of them featured resistance; sometimes Anansi's survival (like that of subjugated slave bodies) depended on blending into the given order.

The repertoire of survival-to-resistance tactics that these tricksters exhibit pertains to complexities within socio-ecological relations and the trickster's ability to shift to express agency on the part of those whose bodies or knowledges have been repressed. Like Brer Rabbit who exhibits polymorphic tendencies, Anansi is a spider, but he sometimes displays human characteristics (a human face or clothes) and a full array of attributes, desires and tactics. Across a wide range of narratives and contexts, Anansi is anything but a static hero. One Jamaican transcriber of the tales suggests that "When things went well he was a man, but when he was in great danger he became a spider, safe in his web high up on the ceiling" (Sherlock 1954). Trickster survival tactics thus might mean understanding/blending into an existing socio-ecological order as necessary to life itself. Resistance tactics are also part of the repertoire of tricksters whose power might emerge from challenging a given socio-ecological order. More recent treatments of Anansi by beloved Jamaican poet, Louise Bennett, for example, feature Anansi as woman who uses her sexuality in novel ways to enact a disruptive agency against British colonial notions of propriety (Vazquez 2009). As Joyce Jonas contends, "Anancy...provokes that dialogue which brings creative disorder into the oppressive structures that dehumanize the world" (1990: 12-13).

Although there are too many themes and messages to convey in any given series of trickster stories, one dominant thematic message is this: one can channel hubris-empowered 'wisdom' in a variety of contexts and enjoy a series of minor victories, but in a world where no one individual or group is the Master Agent, one cannot ultimately control the outcomes or elements in a multi-faceted and complex world. Anansi and Brer Rabbit are representative of an array of human and non-human ways of being in the world. In one entity, there exists a multiplicity. The only way to capture this multiplicity is to continue telling the stories in multiple episodes. No one episode carries the take-away message, the moral of the story, or the defining Anansi/Brer Rabbit. There are only contingent endings amid shifting life situations/scenarios. Such insights from these stories offer potentially powerful orientations at a time during which cultural and material bearings are profoundly shifting.

\section{Trickster Carbon as ongoing cultural and material work}

Bringing the insights of allotropic carbon and trickster stories together enables a certain generative view from which to understand a variety of messy entanglements in the cultural politics of climate change. For the purpose of this article, I lay the imaginative groundwork for future, iterative tales of Trickster Carbon. 
While I do not wish to severely proscribe what these could look like, the preliminary principles below may guide future imaginative work.

\section{Carbon associations are complex and need multiple stories/angles}

There is no purging carbon of its cultural associations that have seemingly slipped from a singularly scientific reading. Carbon as a trope will not be tethered to a strictly scientific understanding, just as carbon as an allotropic element will not be tethered monogamously to the yoke of machines promising limitless progress and development (for some, at the expense of others). For better and for worse, carbon has become a central figure for publics grappling with the shifting terrain of climate change. Rather than disparage carbon's unruliness, though, trickster stories affirm unruliness as a condition of life and make use of this polymorphism as a principal of living in a complex, rapidly-changing world.

If Carbon is understood as a shape-shifter that shifts in certain contexts with certain associations, then the on-going scientific and cultural work remains in the tracing of associations with an understanding of the contingency of these traces

This does not mean that trickster work is not critical, actionable and relevant to present day issues. Trickster stories have traditionally offered critique and points of self-reflection for societies in flux and are not simply static children's stories, as they are often rendered in Euro-Western children's books. As Julius Lester, an African-American re-teller of Brer Rabbit stories states: "Folktales are not cultural artifacts. In actuality, we are the tale and the folktales are a mirror in which we can see (if we know how to see) our particular story" (1987: xx). On a general level and in a timeless manner, trickster stories might serve as mirror of the best and the worst (and the ambiguous in-between) potential of societies given the conditions and contexts that shape them. In our particular time, surely (trickster) carbon inhabits this space for many societies and nations in which Carbon, in its different manifestations has become the source of the loftiest hopes and most disquieting fears. Further, although trickster stories are a reminder of larger-than-human forces and energies, they have always served as way-finding systems for human societies in cultural histories. These are not merely individual stories from which one can derive an ultimate moral statement, but they outline the contours of predicaments and pitfalls that might be common in societies within a given epoch; thus, they offer profound way-finding capacities as simulations (that might complement or disturb the dominance of scientific climate model simulations).

More particularly, trickster stories offer important sites to think through colonial and decolonial questions of heightened importance at a time of climate change

As certain trickster tales have spread from their points of origin, travelled slave ships and mixed with other cultures' stories, one of their most important roles has been to animate a spirit of cultural resilience and power among those whose sense of resilience and power have been compromised through dominating societies who have robbed them of their humanity and untethered them from their geo-cultural bearings (Levine 1977). Thus, trickster stories orient us to think of the ways in which climate change is a symptom of a disjointed world where neither responsibilities nor impacts are equally shared. Sites of fossil fuel extraction and transportation have been, and continue to be located on appropriated Indigenous lands, fostering the disproportionate burden of inevitable trickster hydrocarbon leakages. The climate justice lens of 'common but differentiated responsibilities and impacts' is one part of this orientation that must animate the notion of trickster carbon.

What is more, trickster carbon can serve as a reminder that under the banner of climate change solutions, a new attention to certain forms of carbon provides the conditions for new forms of colonial capture that further exacerbate existing global inequities. Naming a forest a "carbon sink", for example, risks erasing all other complex cartographies of existence and lively social-material interactions within that place. 


\section{Trickster Carbon cannot be trapped or sequestered definitively}

Trickster stories and unfolding scientific understandings of carbon's allotropism lend insights into the inevitable shiftiness of carbon in a larger-than-human world of forces. Attempts to get the quantifying metrics of carbon 'right' in climate scenarios are inevitably subject to shifting carbon cycles that often frustrate mitigation efforts. The pine bark beetle (Dendroctonus ponderosae) in the Pacific Northwest of Canada offers one example of this trickster nature of carbon. Whereas the forests of this region were once regarded as 'carbon sinks' promising to stand as central allies in the attainment of climate change mitigation goals, the presence of bark beetles has transformed forests into net producers of greenhouse gas emissions as a result of the wood decay brought on by the beetles. Just as 'we' think the boreal forests of Canada are going to perform a certain amount of carbon sequestration, the bark beetle speaks back to suggest that all managerial calculations are off. The research of Yale Ecology professor, Oliver Schmitz reports, "an unprecedented loss of trees triggered by the pine beetle outbreak in western North America has decreased the net carbon balance on a scale comparable to British Columbia's current fossil fuel emissions" (Graham Richards 2013). What is more, recent wildfires in these forests (and elsewhere) remind that in a warming world, the anticipated increase of forest fires means that greenhouse gas emissions inventories and forest carbon management plans often grossly miscalculate both the capacity of forests to store carbon, and the ways in which forests on fire can contribute inordinate amount of warming emissions. ${ }^{14}$

This carbon tale starkly reminds us of the enmeshed human and non-human agencies that trouble quantitative accounts and even future-oriented planning of reduction targets; if scenario-planning and targets are based on reductions of emissions from human-specific sources, but do not (indeed cannot in a quantifiable sense) take into account complex ecosystem interactions and unknown variables, then such scenarios and targets cannot lead to the kinds of outcomes that they pretend to. This is not to argue for the off-loading of responsibility for unforeseen emissions onto the bark beetle, but to make the case that our belated apprehension of its carbon impact (as an entangled function of human-induced warming) compels a reorientation towards a politics that anticipates as yet unknown contributions to carbon emissions. Tricksters are amalgams of more than one actor-agent. In their shiftiness, they work with and/or against different figures at every turn; thus, trickster carbon can be read as an entangled larger-than-human story whereby certain human thoughts and actions interact with elemental or compounded carbon (and other actors) in a complex culturalbiospheric system.

To engage the power of Trickster Carbon sensibilities is to keep awake to these animate interactions. Sensibility to these relations suggests that instead of asking non-human agents (like trees) to do the work of mitigation on our behalf as we (especially in the Global North) carry on with 'business-as-usual' carbon emissions, we might re-orient ourselves to more responsible and responsive mitigation efforts away from anthropocentric and asymmetrical growth scenarios.

\section{Trickster Carbon can trace promising attachments for transformative potential}

If "we are the tale" as Lester suggests, then trickster carbon invites us to think 'we' in complex ways that are not simply anthropocentric, nor reflective of one particular story of human development. One of the benefits of the Anansi spider stories according to one Jamaican transcriber, Philip Sherlock, is that when people see a spider they know that he is "more than a spider" and they may think twice about harming him (Sherlock 1954: 2). This aspect of Anansi stories is not to be underestimated in terms of dominant cultural stories depicting the reviled, fear-inducing creepy figure of the spider. If we can see and identify in this creature a range of 'our' traits - from greed to cooperation to wisdom to foolery and more - then we may see a repertoire for critically reflecting upon the struggles of the day and our efforts of living in a community that is not only conceived in human terms. So too may we approach Trickster Carbon, reflecting 'us' as a marker of the best and worst and the in-between of larger-than-human carbon relations at a time of climate change. This

\footnotetext{
${ }^{14}$ While the calculations are still on-going at the time of writing, recent estimates suggest that the 2017 wildfires in British Columbia have contributed three times the annual carbon footprint of the Province. http://www.cbc.ca/news/canada/british-columbia/it-s-alarming-wildfire-emissions-grow-to-triple-b-c-s-annual-carbonfootprint-1.4259306
} 
recognition of commonality, however, must not risk the flattening out of 'self' and 'other' or multiple worlds as 'the same.' One of the messages these stories conveys is that there remains an unknowability in the trickster order that ought to be valued.

There is a related risk here: the potential for cultural appropriation. This is indeed a tricky struggle that must be kept at the forefront of Trickster Carbon stories. Even my position as a 'Jamaican-Canadian' who has never lived in the Caribbean offers a particular interpretation of these stories that emerges from a life immersed within the trappings and privileges of the Global North as a settler on extracted lands. However, as one who has grown up in a transgressive skin among bears, moose, mosquitoes, coyotes and pulp and paper mills in the forests of Lheidli T'enneh territories, I feel an affinity with stories of complex relations with nonhuman animals, and an alienation from many Western Enlightenment myths that have never felt completely my own. Further, these Western Enlightenment myths are proving to be troubled at a time of climate change. Other ways of knowing that have been written off in the past as primitive are now starting to be recognized more widely as sophisticated, robust and better able to merge the cultural and material elements of planetary life (Anatol 2017). David Syring, for example, recounts the power of the "environmental imagination" as a cultural-material orienting mechanism among the stories of the Saraguro peoples of Ecuador. Syring's Saraguro guide and storyteller, Benigno Cagno, highlights the importance of the truth of stories in their relations and respectful interactions with water and fish in local ecologies. Syring contrasts these orienting stories to the "environmental imagination" in dominant North American societies which feature more abstracted and scientific managerial ways of dealing with water 'resources' and invasive species (Syring 2007).

Rather than reducing trickster stories to one element in the often-reduced and instrumentalized acronym TEK (traditional ecological knowledge), these stories might more appropriately align with Indigenous resurgence movements that value the place-based presence of peoples on their territories. As a settler of diasporic migrant communities, my understanding of the cultural stories of Anansi is symptomatic of a certain twice-alienated perspective (once in the movement from of the stories from West Africa/Ghana to Jamaica and the second in the movement of my family from Jamaica to Canada). This perspective animates my understanding and affirmation of trickster shifts and movements in a changing world.

Nonetheless, as a settler who has also most certainly benefitted from colonial relations in this country, I am conscious of the potential de-politicizing move for land-based politics in the affirmation of a diasporic trickster figure. As I now learn from the Anansi stories originating among Indigenous peoples in West Africa, these stories are highly place-based and reflect ecological relations and seasons (droughts, etc.) in the region of their origin (Aardema 1997). These regionally place-based connections must certainly be featured in the powerful offerings of certain trickster stories, for they potentially register how the local and regionally-based (carbon) relations connect to the planetary concerns of climate change. Glen Coulthard and Leanne Simpson's (2016) elaboration of "grounded normativity" serves to centre such important place-based set of practices and knowledge within Indigenous resurgence:

Grounded normativity houses and reproduces the practices and procedures, based on deep reciprocity, that are inherently informed by an intimate relationship to place. Grounded normativity teaches us how to live our lives in relation to other people and nonhuman life forms in a profoundly nonauthoritarian, nondominating, nonexploitive manner. Grounded normativity teaches us how to be in respectful diplomatic relationships with other Indigenous and non-Indigenous nations with whom we might share territorial responsibilities or common political or economic interests. (p.254)

Surely the principles of grounded normativity offer an important intervention in how we consider solutions to climate change in order to avoid the same colonial extractivist mindset (Simpson 2013) that has, in part, 
created the problem; thus, climate change politics must be infused with such land-based understandings. Trickster Carbon as an opening gesture invites such crucial interventions from those on the traditional territories in which their trickster stories have emerged, while recognizing that with the forced global relocation of peoples, certain trickster stories have derived their shifting meanings from within or ambivalently through colonial upheavals where traditional territories are no longer available for many. This difference is important to highlight so that solidarities are not prematurely forced and all justice issues are not collapsed at the expense of land-based politics.

\section{Future Trickster conversations and imaginaries}

What might then 'count' as a Trickster Carbon story? If there is future work in telling these stories more explicitly, as I wager, then how do we move to collect and share these to permit a needed complexity? Trickster tales have no single author but are culturally-shared and evocative of the struggles of the day, so I propose this work as a shared cultural-material venture. I invite people who have grown up with trickster stories as life-orienting to critique/deepen this notion and to proliferate accounts of Trickster Carbon if the notion speaks to them. I cautiously propose that scientifically-infused stories about carbon's allotropism might even count as trickster stories if they concede that:

1) there are multiple stories to be told from multiple perspectives, especially from the perspectives of those cultures whose trickster stories have served as way-finders through cultural and ecological upheaval;

2) they orient toward humility rather than hubris in the management of objects and people;

3) they centre decolonial political aspirations, and

4) they entertain the presence of larger-than-human forces and agency even as they understand that carbon cannot be controlled and can play multiple roles for a variety of agendas.

For some, this idea of Trickster Carbon may seem too theoretical or imaginative to be of material and practical value. This may be true especially for those who have not grown up with trickster stories and/or for those whose formal education has bred the importance of stories out of them (I would have added myself to this latter category until recently, as I am just now coming back to the force of alternative stories that displace the Western Euro-centric education I have received in formal settings). To this charge, I offer the profound power of stories that constantly work to shape worlds, even when we do not recognize them as stories. The history of science is rife with dominant norms and conventions of the day that go unnoticed as stories, only to appear to people in other places and times to have been utterly created and at best, ludicrous and at worst, violent and oppressive. ${ }^{15}$ Further, if we accept, as increasing numbers have, that change is needed to recalibrate and move through the abrupt changes we are encountering, then the work of the imagination is urgently needed. As Susan Griffin suggests:

Like artistic and literary movements, social movements are driven by the imagination...Every important social movement reconfigures the world in the imagination. What was obscure comes forward, lies are revealed, memory shaken, new delineation drawn over the old maps: It is from this new way of seeing the present that hope emerges for the future...Let us begin to imagine the worlds we would like to inhabit, the long lives we will share and the many futures in our hands. (2004: 174)

As climate change challenges us to imagine the worlds we would like to inhabit through creative forwardthinking, we might also remember the continuity of cultural communities whose important cultural-material devices have been forgotten in dominant societies. Trickster Carbon offers the possibility of tracing shifting

\footnotetext{
${ }^{15}$ One such example comes from the scientifically-based notion of eugenics, that has historically robbed certain people of their humanity, their reproductive rights and even their lives.
} 
cultural-material stories that reach into the past, but remain highly relevant in their attunement to ambivalent shifts, and in their constitution within diverse larger-than-human communities. The promise of these stories lies in their re-orienting capacity at a time of potentially dizzying change.

\section{References}

Aardema, V. and L. Desimini. 1997. Anansi does the impossible: an Ashanti tale. New York: Atheneum.

Anatol, G. 2017. Anansi the trickster: contesting Eurocentric knowledge production in the Americas. In W. Raussert (ed.). Routledge companion to Inter-American Studies. London: Routledge.

Archambault II, D. 2017. Standing Rock: the violation of Indigenous peoples' rights. Talk at Cornell University February 17, 2017. http://www.cornell.edu/video/indigenous-rights-standing-rock-sioux

Awesome allotropy. 2010. Nature Materials 9 (11): 867.

Bennett, J. 2010. Vibrant matter: a political ecology of things. Durham: Duke University Press.

Bernstein, S. 2000. Ideas, social structure and the compromise of liberal environmentalism. European Journal of International Relations 6(4): 464-512.

Bhatnagar, D. and D. Goldtooth. 2015. UN promoting potentially genocidal policy at World Climate Summit. ienearth.org.

Birchfield, D.L. 1996. Animal lore and legend - rabbit: American Indian legends. New York: Scholastic.

Bridge, G. 2011. Resource geographies 1: making carbon economies, old and new. Progress in Human Geography. 35: 820-834.

Bumpus, A. and D. Liverman. 2008. Accumulation by decarbonization and the governance of carbon offsets. Economic Geography 84(2): 127-155.

Chomba, S., J. Kariuki, J. Lund and F. Sinclair. 2016. Roots of inequity: how the implementation of REDD+ reinforces past injustices. Land Use Policy 50: 202-213.

Coulthard, G. and L.B. Simpson. 2016. Grounded normativity/place-based solidarity. American Quarterly 68(2): 249-255.

Das, R., M.E Ali, S.B.A. Hamid, S. Ramakrishna and Z.Z. Chowdhury. 2014. Carbon nanotube membranes for water purification: a bright future in water desalination. Desalination 336: 97-109. Researchgate

Gay, D.E. 2003. Southeastern rabbit tales. In J. Brennan (ed.) When Brer Rabbit meets Coyote: AfricanNative American literature. Chicago: University of Illinois Press. Pp. 101-113.

Girvan, A. 2017. Carbon footprints as cultural-ecological metaphors. London: Routledge.

Graham Richards, M. 2013. Pine beetle impact on carbon balance as important as British Columbia fossil fuel use. Tree Hugger. Oct 16.

Griffin, S. 2004. To love the marigold. in P.R. Loeb (ed.). The impossible will take a little while: a citizen's guide to keeping hope alive in a time of fear. New York: Basic Books. Pp. 169-174.

Handbook of Mineralogy http://rruff.info/doclib/hom/chaoite.pdf (accessed May 13, 2013)

Haraway, D. 1988. Situated knowledges: the science question in feminism and the privilege of partial perspective. Feminist Studies 14(3): 575-599.

Hirsch, A. 2010. The era of carbon allotropes. Nature Materials 9: 868-871.

Harris, A. 2000. Speaking the truth by dissembling: necessary ambiguities in the Tar-baby tale. Journal of Literary Studies 16(3-4): 58-75.

Hulme, M. 2014. Can science fix climate change? A case against climate engineering. Cambridge: Polity.

Hunter, J. 2010. Pine beetles transform BC forests into greenhouse enemy. The Globe and Mail. January 8.

Jonas, J. 1990. Anancy in the great house: ways of reading West Indian Fiction. Westport, CT: Greenwood Publishing.

Koteyko, N. 2010. Mining the internet for linguistic and social data: an analysis of 'carbon compounds' in web feeds. Discourse and Society 21(6): 655-674. 
Koteyko, N. 2012. Managing carbon emissions: a discursive presentation of 'market-driven sustainability' in the British media. Language and Communication 32(1): 24-35.

Kunuk, Z. and I. Mauro. 2010. Quapirangajug - Inuit knowledge and climate change (film). Igloolik, Nunavut: Igloolik Isuma Productions and Kunuk Cohn Productions.

Lester, J. 1987. The tales of Uncle Remus: the adventures of Brer Rabbit. New York: Dial Books.

Levine, L. 1977. Black culture and black consciousness: Afro-American folk thought. New York: Oxford University Press.

Lifton, J. 2012. Graphite and rare earth metals for the $21^{\text {st }}$ century: Interview. The Gold Report. www.theaureport.com.

Marshall, E. 2012. Anansi's journey: a story of Jamaican cultural resistance. Kingston: University of West Indies Press.

McGinty, M. and M. Bang. 2016. Narratives of dynamic lands: science education, Indigenous knowledge and possible futures. Cultural Studies of Science Education 11: 471-475. Researchgate

Miodownik, M. 2006. Carbon culture. Materials Today 9(6): 6.

Mitchell, T. 2011. Carbon democracy: political power in the age of oil. New York; London: Verso Books.

Mukhopadhyay, P. and R.K. Gupta. 2013. Graphite, Graphene, and their polymer nanocomposites. Boca Raton, FL: CRC Press.

Nerlich, B. 2012. 'Low carbon' metals, markets and metaphors: the creation of economic expectations about climate change mitigation. Climatic Change 110(1-2): 3-52.

NOAA. Nd. What is ocean acidification?

Rennie, R. 2016. Allotropy. In A dictionary of chemistry. Oxford: Oxford University Press.

Rutledge, G. 2013. The epic trickster in American literature: from Sunjata to Soul. New York: Routledge.

Salifu, F. n.d. Why Anansi has eight skinny legs. World Stories.

Sherlock, P.M. 1954. Anansi the spider man. New York: Thomas Y. Crowell.

Simpson, L. with N. Klein. 2013. Dancing the world into being. Yes Magazine. 5 March.

Syring, D. 2007. Sweet water and exotic fish: ethnographic reflections of environmental imaginations in Ecuador and the Great Lakes. Anthropology and Humanism 32(1): 62-80.

Vest, J. 2000. From bobtail to Brer Rabbit: Native American influences on Uncle Remus. American Indian Quarterly 24 (1): 19-43.

Walker, A. 2012. Uncle Remus, no friend of mine. The Georgia Review 66(3): 635-637.

World Rainforest Movement. 2014. Forced relocation of Sengwer people proves urgency of cancelling REDD. World Rainforest Movement. 